\title{
Brezar, V. (2014). Traktat o detajlu v arhitekturi [A Treatise on Detail in Architecture]. Ljubljana: University of Ljubljana, Faculty of Architecture. 51 p. ISBN 978- 961-6823-56-2
}

Reviewed by Domen ZuPANČIČ

Detail entails materialisation of the idea of function. A detail shows elements that have been successfully assembled to form a harmonious whole. The Viikki Church in Finland is such an example. JKMM architects realised a crosslap joint of six timber construction elements resulting in the gracious spatial network of the ceiling. The joint reaches beyond the notion of construction, it serves as an emblem of the genetic code and the embodiment of architecture (Tectonics in Architecture, Čeferin, P. (Ed.), 2014, p. 30). The book "A Treatise on Detail in Architecture" conveys its message in a similar way. The challeng-

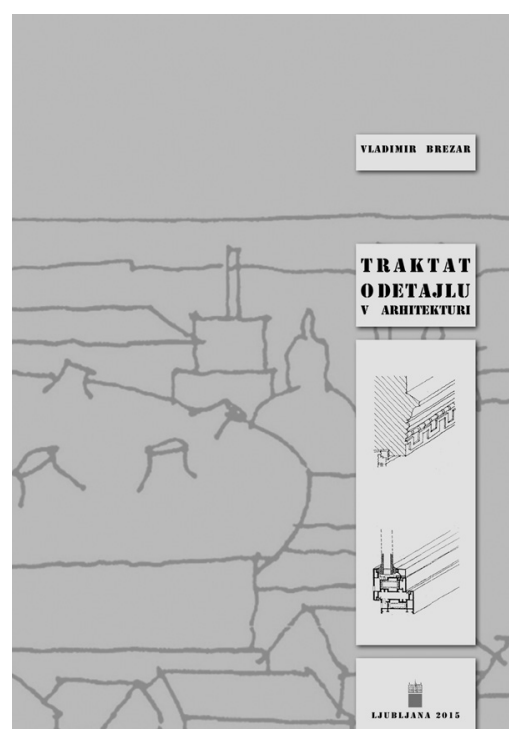
ing title does not reflect a pretentious wish on the part of the author to stand out in the field of the description of architecture; rather, it embodies the fundamental idea of communicating his own experiences to readers.

In terms of content, the text is a genuine academic treatise corroborated by drawings. The black-and-white line drawings are perfectly theological. With a Franciscan-like simple clarity, they address beginners, enthusiasts in the field of architecture becoming acquainted with the semantics and grammar of architecture. Brezar sums up his introductory thoughts with a depiction of "the perennial" division between different methods of teaching at the Ljubljana school. He wilfully unveils the proverbial opposition between Vurnik and Plečnik, which both masters also projected onto their students.

The introduction commences with the original state (genesis) of detail, with the search for the sustainable existence of a structure. In the process, the author sensibly highlights the area of the multiple use of elements from 
basic constructional solutions to the styling of elements (columns). Due to the economy of the solutions, the designer's creative potential passes onto the field of formalism by way of the parameters and coding of architectural elements. Brezar conscientiously links the theme with anthropology and the technology for realising details.

In terms of meaning, the chapter "Compounding and Assemblage" provides real evidence of the wisdom arising from the author's experiences. The text is broken down into sub-chapters: Assemblage, Joint, Gravitation and Frame Recess. The creative process is directed by these very basic elements that make sense of the assemblages. Assemblage means putting all of the parts together to form a whole featuring fresh characteristics and functions. Every assembly contains a contact, a juncture, frequently as a non-material joint in the form of a shadowy line. The author also underscores the meaning of detail by quoting Loos, Bauhaus and Le Corbusier, observing how their ideas were reflected back to Europe from the United States. This architecture of pure forms, free from superfluous ornamentation, was often carelessly imitated and frequently poorly materialised.

Alongside the criticism, there is a range of schemes and drawings of elements that cover topics from the issue of assembling equal elements into a composition to the materialisation of a point, a straight line and a plane. Brezar also articulates a thought that is relevant to his work: What is the daring wish to design a building enclosure, and the tendency towards a monolithic and continuous surface? It is believed that this remains an unachievable dream, but that is not quite true; there is a trick, a trick for the observer. At this point, the author leaves out the contemporary facade envelopes with integrated LED lights, because such structures act merely as media elements in a technocratic urban space. He surely wilfully omitted this content, given that he carries on in a traditional, basic manner with the chapter "Detail as a Message". In this chapter, he critically refers to the impoverishment of forms, which he clearly illustrates by comparing a Baroque table leg with the leg of a modern table, where the leg merely stands for "a high degree of surface treatment". A qualitative leap in the content of the book occurs with the chapter on semantic paradox, where the text comes closest to a treatise on detail. A detail is not a mere functional element, it is also important for the observer. The paradox of simplifying architectural elements is tied up with new, contemporary materials that make the existence of these architectural solutions possible.

Where does the essence of the paradox reside? Brezar discerns its locus in the enthusiasm to use contemporary materials for shaping assemblages, an enthusiasm accompanied by frequent beginners' mistakes such as failing to 
sufficiently consider the laws of nature and neglecting the holistic approach while conferring sense on and grasping the function of architecture. The most evident example is the comparison between a bifora and a contemporary window frame. Repetitions of details and assemblages on a facade are inevitable, but they can be individualised, as every embedment is unique.

The theme of repetition and uniqueness of embedment is described insufficiently in the theory of architecture. C. Alexander is often the chief source, with his records of rites and life habits associated with architectural elements.

The conclusion of the treatise is left hanging in mid-air with a paragraph about "non-houses", "blob buildings" and similar structures in the architectural landscape, which is doubtlessly evidence of the individualisation of contemporary Western society. Everyone is becoming their own axis of life, everydayness is becoming a trend, a vogue. Blob building necessitates a non-treatise, i.e., verbal explanation. Here the treatise reaches the point of inflection; Brezar quotes Alberti's thought about the healing of grief and the overcoming intimate feelings of decay by skilfully observing built edifices. This is no doubt a self-immunising reaction of the treatise's author. There is light at the end of the corridor!

Brezar's selection of supplements reveals part of his architectural intimacy, ranging from unveiling concept composition and the realisation of details, to the imaginariness of a staircase handrail. These supplements are not a random collection of drawings to fill vacant pages; they wisely determine the end of the treatise and announce the development of a virtual world in architecture accepted by the architectural community as being equal to the real one.

The monograph on detail, written in Slovenian and complemented with sketches, has enormous potential for the description of architecture.

Architect and professor Vladimir Brezar is a Slovenian version of the internationally acknowledged author and excellent draughtsman Francis Ching, who works in the USA. 